\title{
Ethanol Production from Various Sugars by Strains of Pachysolen tannophilus Bearing Different Numbers of Chromosomes
}

\author{
By RYSZARD MALESZKA, ALLEN P. JAMES* AND HENRY SCHNEIDER \\ Division of Biological Sciences, National Research Council of Canada, Ottawa, \\ Ontario K1A 0R6, Canada
}

(Received 30 November 1982)

\begin{abstract}
Increasing chromosome number of Pachysolen tannophilus above the haploid level increased the yield of ethanol from D-xylose. There was a large increment on going from the haplophase to the diplophase, and the highest yields were obtained with either a triploid or a probable tetraploid, depending on the concentration of D-xylose. In addition, the rate of ethanol production from $\mathrm{D}$ xylose and D-glucose increased, with the increment being larger on D-xylose. On D-galactose, the amount of ethanol produced within a given time also increased. The level of a by-product from D-xylose, xylitol, decreased on going from a haploid to higher ploidy, but there was no discernible trend for two other by-products, acetic acid and arabinitol. Increasing ploidy increased growth rate on D-galactose, but not appreciably on D-xylose. The altered properties on D-xylose of the strains tested were not due to increased levels of either D-xylose reductase or xylitol dehydrogenase, nor probably of alcohol dehydrogenase.
\end{abstract}

\section{INTRODUCTION}

Pachysolen tannophilus is one of the better producers of ethanol from D-xylose (Schneider et al., 1983). It also functions well in some mixtures of pentoses and hexoses (Neirinck et al., 1982). However, several of its properties require improvement before it can be used for industrial purposes. The rate at which alcohol is produced from $D$-xylose was found to be about a quarter of that from D-glucose, while the rate of growth on D-xylose was found to vary with conditions from a quarter to a tenth of that of Saccharomyces cerevisiae on D-glucose. Although yields can be high with low concentrations of $\mathrm{D}$-xylose, $\sim 79 \%$ of theoretical on $2 \%(\mathrm{w} / \mathrm{v})($ Maleszka et al., 1981), they decrease with higher sugar concentrations. In addition, several by-products can be produced at the expense of ethanol: xylitol, arabinitol and acetic acid (Neirinck et al., 1982).

Industrial strains of yeast have been reported to be polyploid or aneuploid (Burrows, 1979), suggesting that an increased number of chromosomes is advantageous. A systematic increase with increasing ploidy in the rate of ethanol formation by $S$. cerevisiae from D-glucose has been demonstrated (Scheda, 1963). Recently, a genetic system for $P$. tannophilus was described which permits tetrad analysis and the construction of diploids (James \& Zahab, 1982) and polyploids (James \& Zahab, 1983). The present paper describes several aspects of ethanol production and by-product formation from several carbon sources in a ploidy series of $P$. tannophilus.

\section{METHODS}

Media. The medium was 2 or $4 \%(\mathrm{w} / \mathrm{v})$ sugar in $0.67 \%(\mathrm{w} / \mathrm{v})$ yeast nitrogen base (YNB), complete or without amino acids (Difco), as specified. Auxotrophic requirements were added at a level of $40 \mu \mathrm{g} \mathrm{ml}^{-1}$. Sterilization was by filtration. The temperature for all experiments was $30^{\circ} \mathrm{C}$.

Growth rate. Growth was followed by optical density measurements at $600 \mathrm{~nm}$ using a Coleman Model 275 spectrophotometer. Fifty millilitres of medium in a $500 \mathrm{ml}$ Erlenmeyer flask with a side arm was inoculated to an $\mathrm{OD}_{600}$ of $0.04-0.07$. The flask was stoppered with a porous foam plastic plug and shaken at 150 r.p.m. on a gyrotary shaker. 
Ethanol yield. Ethanol production for yield measurements was followed during aerobic recycling in rotated tubes (Schneider et al., 1981). The volume of medium in experiments with D-xylose was $10 \mathrm{ml}$. The recycling intervals were 24 and $48 \mathrm{~h}$ with 2 and $4 \%$ D-xylose respectively. As cell density increased with recycling, the ethanol concentration after each cycle increased to a limiting value after the fourth or fifth. Only the limiting value is reported. The initial cell density in the first cycle was $10-12 \mathrm{mg} \mathrm{dry} \mathrm{wt} \mathrm{ml}^{-1}$; the cell density was $20-24 \mathrm{mg}$ dry wt $\mathrm{ml}^{-1}$ at the end of the recycle series. The cells used were pregrown aerobically in D-xylose and concentrated by centrifugation.

Ethanol production from $2 \% \mathrm{D}$-galactose was also measured in rotated tubes, but with a medium volume of $6 \mathrm{ml}$. The cells were initially grown on $\mathrm{D}$-galactose to an $\mathrm{OD}_{600}$ of $0 \cdot 8-1.0$ and then resuspended in the rotated tubes in fresh medium after fivefold concentration. Ethanol level increased with time, and only the value after $72 \mathrm{~h}$ is quoted.

Ethanol yield was computed assuming (i) that all of the sugar had been utilized and (ii) that the maximum theoretical productivity was $0.51 \mathrm{~g}$ ethanol per $\mathrm{g}$ sugar for $\mathrm{D}$-xylose as well as for $\mathrm{D}$-galactose. Use of this factor for $\mathrm{D}$-xylose is based on the view (Wang et al., 1980) that the pentose is converted to D-xylulose 5-phosphate, which is then converted non-oxidatively by enzymes of the pentose phosphate pathway into intermediates of the EmbdenMeyerhof-Parnas pathway, after which this latter pathway is followed.

Rate of ethanol production. After seven cycles on D-xylose as described above, the cells were resuspended in media containing either $2 \% \mathrm{D}$-xylose or $2 \% \mathrm{D}$-glucose. The amount of ethanol produced in $4 \mathrm{~h}$ was then determined, and expressed as mg ethanol produced (mg dry wt cells) ${ }^{-1} \mathrm{~h}^{-1}$.

By-product formation on D-xylose. Cells were grown aerobically on $4 \%$ D-xylose $(266.5 \mathrm{mM})$ in $0.67 \%$ YNB (complete) to an $\mathrm{OD}_{600}$ of 0.75 . They were then concentrated in $4 \% \mathrm{D}$-xylose in $0.67 \% \mathrm{YNB}$ to yield $45 \mathrm{mg}$ dry wt $\mathrm{ml}^{-1}$. A $10 \mathrm{ml}$ portion of suspension was cultured in a rotated tube for $34 \mathrm{~h}$ at $30^{\circ} \mathrm{C}$, after which the cells were removed by centrifugation, and the supernatant medium was analysed for xylitol, acetic acid and arabinitol. A culture period of $34 \mathrm{~h}$ was chosen, since this interval was required to ensure complete consumption of all the Dxylose, and it was of interest to determine the concentration of the by-products remaining after complete utilization of the original carbon source.

Analytical methods. Ethanol and acetic acid were determined using the column and conditions described previously (Maleszka \& Schneider, 1982). Xylitol and arabinitol were determined by HPLC using an Aminex HPX-87P column (Bio-Rad).

Enzyme activity. Cultures $(200 \mathrm{ml})$ were grown for $16-18 \mathrm{~h}$ to an $\mathrm{OD}_{600}$ of $0.650-0.700$ in $4 \% \mathrm{D}-\mathrm{xylose}$ in $0.67 \%$ YNB without amino acids at $30^{\circ} \mathrm{C}$ and the cells were harvested by centrifugation. The cells were washed with $0.2 \mathrm{M}$ potassium phosphate, $\mathrm{pH} 7.5$, and resuspended in the same buffer, usually $5 \mathrm{ml}$. The suspensions were then sonicated while immersed in an ice bath after adding $250 \mathrm{mg}$ alumina (Type 305, Sigma) to improve breakage. Three $1 \mathrm{~min}$ bursts were employed, allowing time for cooling between each. The samples were clarified by centrifugation at $10000 \mathrm{~g}$. Activity for D-xylose reductase (EC 1.1.1.21) (cofactor NADPH) and xylitol dehydrogenase (EC 1.1.1.9) (cofactor NAD) were measured as described previously (Maleszka et al., 1983). The activity of alcohol dehydrogenase (EC 1.1.1.1) was measured as described by Lutstorf \& Megnet (1968). Protein was determined by the Lowry method.

\section{RESULTS}

\section{Preliminary screening}

A preliminary survey was carried out on $4 \%$ D-xylose in $0.67 \%$ YNB to determine if an increase in chromosome number caused an increase in growth rate and in ethanol yield. Sixtyone strains described previously by James \& Zahab (1983), were used, including 11 haploids, 4 diploids, 2 triploids, and a probable tetraploid. The remainder were aneuploids.

The generation time of the majority of the strains was within $\pm 5 \%$ of the mean of $3.0 \mathrm{~h}$. The most rapid grower was the diploid NRRL Y2460-\#2. Its generation time was about $10 \%$ greater than that of the haploid from which it was directly derived, NRRL Y2460, the generation time of which was $3.0 \mathrm{~h}$.

Ethanol yield generally increased with chromosome number. For more detailed study on Dxylose, 18 strains were chosen which represented the trends observed.

\section{Ethanol yield from D-xylose}

Increasing chromosome number was associated with increased ethanol yield from $2 \%$ and from $4 \%$ D-xylose (Table 1) under the standard set of conditions used to compare the various strains. The largest increment was between haploids and diploids, notably between the haploid NRRL Y2460 and its isogenic diploid NRRL Y2460-\#2. There was considerable variability 
Table 1. Yield and rate of ethanol production from D-xylose and D-galactose by strains bearing different numbers of chromosomes

\begin{tabular}{|c|c|c|c|c|c|c|c|c|}
\hline \multirow[b]{2}{*}{ Strain } & \multirow[b]{2}{*}{ Ploidy } & \multirow[b]{2}{*}{ Phenotype* } & \multicolumn{2}{|c|}{$\begin{array}{c}\text { Ethanol yield on } \\
\text { D-xylose } \dagger \text { at: }\end{array}$} & \multirow{2}{*}{$\begin{array}{c}\text { Ratio } \\
a / b\end{array}$} & \multicolumn{2}{|c|}{$\begin{array}{l}\text { Rate of ethanol } \\
\text { production } \ddagger \text { from: }\end{array}$} & \multirow{2}{*}{$\begin{array}{c}\text { Ratio } \\
c / d\end{array}$} \\
\hline & & & (a) $2 \%$ & (b) $4 \%$ & & (c) Xylose & (d) Glucose & \\
\hline NRRL，Y2460 & $n$ & WT & $69 \cdot 1$ & $58 \cdot 8$ & $1 \cdot 18$ & 46 & 200 & $4 \cdot 35$ \\
\hline NRRL Y2463 & $n$ & WT & $68 \cdot 5$ & $58 \cdot 8$ & $1 \cdot 16$ & 50 & 210 & $4 \cdot 20$ \\
\hline P106-10B & $n$ & $\mathrm{Ade}^{-}$ & $69 \cdot 6$ & $56 \cdot 4$ & $1 \cdot 23$ & 42 & - & - \\
\hline P56- \#3-3B $\S$ & $<2 n$ & Lys $^{-}$ & $78 \cdot 4$ & $66 \cdot 2$ & $1 \cdot 18$ & 42 & 175 & $4 \cdot 17$ \\
\hline P56-\#3-11D $\S$ & $<2 n$ & Lys $^{-}$ & $58 \cdot 8$ & $51 \cdot 5$ & $1 \cdot 14$ & 17 & 150 & $8 \cdot 82$ \\
\hline P56-\#3-12D $\S$ & $<2 n$ & $\mathrm{Arg}^{-}$ & $73 \cdot 5$ & $56 \cdot 4$ & $1 \cdot 30$ & 54 & 235 & $4 \cdot 35$ \\
\hline P56-\#3-7A§ & $<2 n$ & Arg $^{-}$Lys $^{-}$ & $78 \cdot 4$ & $58 \cdot 8$ & $1 \cdot 33$ & - & - & - \\
\hline P56-\#3-3C & $<2 n$ & $\mathrm{Ade}^{-}$ & $74 \cdot 5$ & $59 \cdot 3$ & $1 \cdot 26$ & - & - & - \\
\hline NRRL Y2460-\#2|| & $2 n$ & WT & $80 \cdot 4$ & $62 \cdot 7$ & $1 \cdot 28$ & 49 & 205 & $4 \cdot 18$ \\
\hline P56-\#3-13D & $2 n$ & WT & $78 \cdot 4$ & $59 \cdot 8$ & $1 \cdot 31$ & 60 & 235 & $3 \cdot 91$ \\
\hline P56-\#2 & $3 n$ & WT & $81 \cdot 3$ & $68 \cdot 6$ & $1 \cdot 18$ & 61 & 240 & 3.93 \\
\hline P56-\#3 & $3 n$ & WT & $81 \cdot 3$ & $68 \cdot 6$ & $1 \cdot 19$ & 63 & 230 & $3 \cdot 65$ \\
\hline P56-\#8 & $3 n$ & WT & $82 \cdot 3$ & $70 \cdot 0$ & $1 \cdot 18$ & 62 & 230 & $3 \cdot 70$ \\
\hline P45-\#6 & $<4 n$ & WT & $76 \cdot 4$ & $65 \cdot 2$ & $1 \cdot 17$ & 80 & 230 & $2 \cdot 87$ \\
\hline P45- \#7 & $<4 n$ & WT & $82 \cdot 3$ & $68 \cdot 6$ & $1 \cdot 20$ & 63 & 250 & 3.96 \\
\hline P45-\#9 & $<4 n$ & WT & $81 \cdot 4$ & $67 \cdot 6$ & $1 \cdot 20$ & 86 & 235 & $2 \cdot 73$ \\
\hline$P 45-\not 16$ & $<4 n$ & WT & $81 \cdot 4$ & $65 \cdot 2$ & $1 \cdot 25$ & 80 & 250 & $3 \cdot 13$ \\
\hline P45-\#14 & $4 n(?)$ & WT & $83 \cdot 3$ & $67 \cdot 2$ & $1 \cdot 24$ & 84 & 250 & 2.97 \\
\hline \multicolumn{9}{|c|}{$\begin{array}{l}\text { * Not measured. } \\
\dagger \text { WT, wild-type. The genotype of strain P106-10B is ade } 2-1 \text {. } \\
\ddagger \text { Expressed as a percentage of the theoretical value. } \\
\ddagger \text { Expressed as mg ethanol (mg dry wt cells) })^{-1} \mathrm{~h}^{-1} \text {. The concentration of both xylose and glucose was } 2 \% \text {. } \\
\text { § Auxotrophic segregants of the triploid P56- } \$ 3 \text { (James \& Zahab, 1983) } \\
\text { Diploid of NRRL Y } 2460 \text {. }\end{array}$} \\
\hline
\end{tabular}

among the aneuploids. The highest yield with $2 \%$ D-xylose $(83.3 \%$ of theoretical) was with a probable tetraploid (P45-\#14), and on $4 \%$ D-xylose (70\% of theoretical), with a triploid (P56-\#8). These values exceed those for a wild-type (NRRL Y2460) by $14.2 \%$ on $2 \%$ D-xylose, and by $11 \%$ on $4 \% \mathrm{D}$-xylose.

The yield of ethanol was greater on $2 \%$ than on $4 \%$ D-xylose. The ratio of the yields from the two concentrations varied with the strain, but there was no systematic trend with chromosome number. Thus, yield on both $2 \%$ and $4 \% \mathrm{D}$-xylose increased proportionately, in general.

Stability of the strains was assessed by measuring ethanol production and yield in recycle experiments lasting 3 weeks. The values obtained were the same within $\pm 2 \%$ of those after the fourth or fifth cycle, shown in Table 1. An additional test for stability, and also for internal consistency and reproducibility, was provided by the triploids P56-\#2, P56-\#3 and P56-\#8. They were independent isolates from the same cross and behaved essentially identically.

\section{Rate of production of ethanol from D-xylose and D-glucose}

The increase in ethanol yield from D-xylose could be due partly to an increased rate of production. The rate of ethanol production increased generally with chromosome number, but aneuploids did not follow the trend. The greatest rate on D-xylose was with the aneuploid P45- \#9, $86 \mathrm{mg}$ ethanol (mg dry wt) $)^{-1} \mathrm{~h}^{-1}$, and it was 1.87 times that of a wild-type haploid (NRRL Y2460). The next greatest was with the probable tetraploid P45-\#14, at 1.83 times the haploid rate.

The rate of production of ethanol from D-glucose also increased with chromosome number. However, the increase in rate with D-xylose was larger than that with D-glucose. The glucose/xylose rate ratio was 2.73 with the strain giving the highest rate on D-xylose, P45- \#9, and 4.35 for a wild-type haploid (NRRL Y2460). 
Table 2. Formation of by-products from D-xylose by strains bearing different numbers of chromosomes

The initial concentration of D-xylose was $266.5 \mathrm{mM}$. The D-xylose was totally consumed during the $34 \mathrm{~h}$ incubation period.

\begin{tabular}{|c|c|c|c|c|}
\hline \multirow[b]{2}{*}{ Strain } & \multirow[b]{2}{*}{ Ploidy } & \multicolumn{3}{|c|}{ Final concn $(\mathrm{mM})$ of: } \\
\hline & & Xylitol & Acetic acid & Arabinitol \\
\hline NRRL Y2460 & $n$ & 93.7 & $8 \cdot 3$ & $3 \cdot 2$ \\
\hline NRRL Y2464 & $n$ & $90 \cdot 7$ & $6 \cdot 1$ & $5 \cdot 6$ \\
\hline NRRL Y $2460-\# 2$ & $2 n$ & $75 \cdot 6$ & $10 \cdot 0$ & $9 \cdot 4$ \\
\hline P39-\#2 & $<3 n$ & $78 \cdot 2$ & $6 \cdot 6$ & $5 \cdot 7$ \\
\hline P56-\#3 & $3 n$ & $79 \cdot 6$ & $6 \cdot 3$ & $3 \cdot 7$ \\
\hline P45-\#16 & $<4 n$ & $71 \cdot 0$ & $10 \cdot 8$ & $5 \cdot 7$ \\
\hline P45-\#14 & $4 n(?)$ & $83 \cdot 5$ & $5 \cdot 6$ & $3 \cdot 1$ \\
\hline
\end{tabular}

Table 3. Ethanol production and growth on $2 \% \mathrm{D}$-galactose by strains bearing different numbers of chromosomes

\begin{tabular}{|c|c|c|c|c|}
\hline Strain* & Ploidy & $\begin{array}{c}\text { Ethanol yield } \\
(\% \text { of theoretical })\end{array}$ & $\begin{array}{c}\text { Acetic acid } \\
(\%, w / v)\end{array}$ & $\begin{array}{l}\text { Generation } \\
\text { time }(\mathrm{h})\end{array}$ \\
\hline NRRL Y 2460 & $n$ & $27 \cdot 0$ & $0 \cdot 15$ & 24 \\
\hline NRRL Y2460-\#2 & $2 n$ & $43 \cdot 1$ & $0 \cdot 001$ & 14 \\
\hline P39-\#1 & $3 n(?)$ & $37 \cdot 2$ & 0.001 & - \\
\hline P39-\#3 & $2 n(?)$ & $43 \cdot 1$ & 0.004 & 16 \\
\hline P45-\#10 & $<4 n$ & $56 \cdot 4$ & 0.001 & 10 \\
\hline P45-\#16 & $<4 n$ & $40 \cdot 4$ & $0 \cdot 001$ & - \\
\hline P45-\#14 & $4 n(?)$ & $40 \cdot 4$ & 0.001 & - \\
\hline
\end{tabular}

\section{By-product formation}

Three of the major by-products produced from D-xylose are xylitol, acetic acid and arabinitol. The amount of acetic acid increased as the amount of oxygen available to the culture decreased, as shown by varying medium volume under an otherwise standard set of culture conditions. Among a series of strains differing in chromosome number, which were picked without preselection (Table 2), the amount of xylitol formed by the haploids was larger than that of the strains bearing higher numbers of chromosomes. Notably, there was a large difference between the haploid NRRL Y2460 (final xylitol concentration $93.7 \mathrm{mM}$ ) and its isogenic diploid NRRL Y2460-\#2 (75.6 mM). There was no consistent trend for acetic acid or arabinitol production. The experiments were carried out with a high cell density, $45 \mathrm{mg} \mathrm{ml}^{-1}$. Oxygen availability to the culture was very low under the conditions used, and effects of ploidy on acetic acid formation could, therefore, be monitored.

\section{Ethanol production and growth on D-galactose}

Pachysolen tannophilus grows slowly on D-galactose, the doubling time on $2 \%$ being $24 \mathrm{~h}$ versus $\sim 4 \mathrm{~h}$ on $2 \%$ D-xylose under identical conditions (Maleszka et al., 1982). Ethanol yields are also very low, $<10 \%$ of theoretical, although improvement is obtained by using cell recycling (Maleszka et al., 1982). Recently a mutant which grows faster on D-galactose, but not D-xylose, was isolated with improved ethanol production behaviour on the hexose (Neirinck et al., 1982). The effect of chromosome number on ethanol production from D-galactose was investigated to determine if improved yields could also be obtained in this way.

Seven strains were tested which were picked without preselection (Table 3). As with D-xylose, the amount of ethanol produced within a given period of time tended to increase with chromosome number, but an aneuploid, P45-\#16, produced as much as the probable tetraploid, P45-\#14, and more than a triploid, P39-\#2. However, in contrast to D-xylose, there was appreciable enhancement in growth rate with increased ploidy. In addition, the polyploids produced less acetic acid on D-galactose than the haploid. 
Enzyme activity

To aid in evaluating the reasons for some of the improvements observed, the activity of two enzymes of D-xylose catabolism and of alcohol dehydrogenase was investigated in cell extracts of strains differing in chromosome number. The strains used were NRRL Y2460 ( $1 n)$, NRRL Y2460-\#2 (2n), P56-\#1 (3n), P56-\#2 (3n) and P45-\#14 (4n?). There was no significant change with chromosome number in the activity of the first two enzymes thought to be responsible for the catabolism of D-xylose. The activities of D-xylose reductase (D-xylose $\rightarrow$

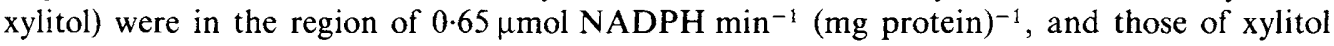

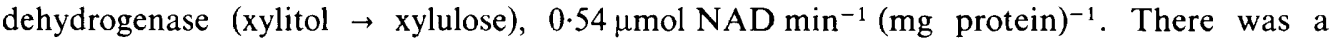
significant difference in alcohol dehydrogenase activity between the tetraploid and the other strains: $1.018 \pm 0.064$ (s.D.) $\mu \mathrm{mol} \mathrm{min}^{-1}(\mathrm{mg} \text { protein })^{-1}$ for the tetraploid and $0.831 \pm 0.033$ for the haploid. However, this difference is small, while the greatest increase in ethanol production characteristics were between haploids and diploids.

\section{DISCUSSION}

Increasing chromosome number improved aspects of ethanol production by $P$. tannophilus from several carbon sources, notably $\mathrm{D}$-xylose. In addition the level of a by-product from $\mathrm{D}$ xylose, xylitol, was reduced. Thus, the use of polyploids seems a useful approach to obtain strains which would perform more efficiently in producing ethanol.

Some of the effects observed with increasing chromosome number probably reflect complex physiological phenomena. An example is the increase in the rate of ethanol production from Dxylose in the absence of significantly changed activities of some enzymes involved in the catabolism of D-xylose or of alcohol formation. Another is the appreciable increase of growth rate on D-galactose, but not D-xylose. However, the improvements in the rate and yield of ethanol production on D-xylose may result from an increase in number of one or more particular chromosomes, rather than from multiplication of the entire genome. This view is supported by the lysine-requiring aneuploids P56-\#3-3B and P56-\#3-11D, which are segregants of the triploid P56-\#3. They bear the same marker, but exhibit significant differences in yield and rate. In addition, the aneuploids generally differ among themselves, but in one or another respect, some are as good as the triploids or the probable tetraploid. Thus, a suitable aneuploid might have the best combination of improvement in yield and rate.

Pachysolen tannophilus seems to bear a relatively small number of chromosomes, 5 to 7 (James \& Zahab, 1983). It might therefore be possible to study systematically, and hence improve, aspects of ethanol production as a function of the number of particular chromosomes.

This paper is NRCC Publication no. 21314.

\section{REFERENCES}

Burrows, S. (1979). Baker's yeast. In Microbial Biomass, vol. 4, pp. 31-64. Edited by A. H. Rose. London: Academic Press

JAMES, A. P. \& ZAHAB, D. (1982). A genetic system for Pachysolen tannophilus, a pentose-fermenting yeast. Journal of General Microbiology 128, 2297-2301.

JAMES, A. P. \& ZAHAB, D. (1983). The construction and genetic analysis of polyploids and aneuploids of the pentose-fermenting yeast, Pachysolen tannophilus. Journal of General Microbiology 129, 2489-2494.

Lutstorf, U. \& MEgnet, R. (1968). Multiple forms of alcohol dehydrogenase in Saccharomyces cerevisiae. Archices of Biochemistry and Biophysics 126, 933-944.

MALESZKA, R. \& SCHNEIDER, H. (1982). Fermentation of D-xylose, xylitol and D-xylulose by yeasts. Canadian Journal of Microbiology 28, 360-363.
MaleszKa, R., Veliky, I. A. \& SCHNeider, H. (1981). Enhanced rate of ethanol production from D-xylose using recycled or immobilized cells of Pachysolen tannophilus. Biotechnology Letters 3, 415-420.

MaleszKa, R., WANG, P. Y. \& SChNeIder, H. (1982). Ethanol production from D-galactose and glycerol by Pachysolen tannophilus. Enzyme and Microbial Technology 4, 349-352.

MaleszKa, R., Neirinck, L. G., James, A. P., Rutten, H. \& Schneider, H. (1983). Xylitol dehydrogenase mutants of Pachysolen tannophilus and the role of xylitol in D-xylose catabolism. FEMS Microbiology Letters 17, 227-229

Neirinck, L. G., Maleszka, R. \& Schneider, H. (1982). Alcohol production from sugar mixtures by Pachysolen tannophilus. In Fourth Symposium on 
Biotechnology in Energy Production and Conservation, Biotechnology and Bioengineering Symposium, No. 12, pp. 161-169. Edited by C. D. Scott. New York: John Wiley.

SCHEDA, R. (1963). Untersuchungen über die Maltoseund Glucosevergärung bei homozygoten Hefestämmen mit verschiedenen Genomzahlen. Archiv für Mikrobiologie 45, 65-100.

SchNeIDER, H., WANG, P. Y., Chan, Y. K. \& MaleszKA, R. (1981). Conversion of D-xylose into ethanol by the yeast Pachysolen tannophilus. Biotechnology Letters 3, 89-92.
Schneider, H., MaleszKa, R., Neirinck, L. G., Veliky, I. A., WaNG, P. Y. \& Chan, Y. K. (1983). Ethanol production from D-xylose and several other carbohydrates by Pachysolen tannophilus and other yeasts. In Advances in Biochemical Engineering/ Biotechnology. Edited by A. Fiechter. Berlin: Springer (in the Press).

WANG, P. Y., Shopsis, C. \& SChNeIder, H. (1980). Fermentation of a pentose by yeasts. Biochemical and Biophysical Research Communications 94, 248-254. 